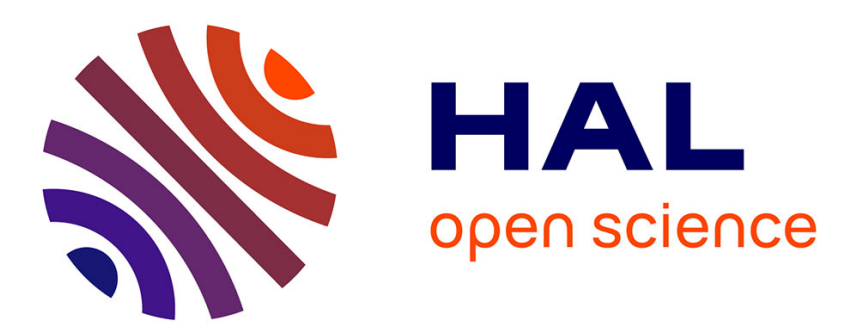

\title{
Impact of land cover change on surface climate: Relevance of the radiative forcing concept
}

E. L Davin, N. de Noblet-Ducoudré, P. Friedlingstein

\section{To cite this version:}

E. L Davin, N. de Noblet-Ducoudré, P. Friedlingstein. Impact of land cover change on surface climate: Relevance of the radiative forcing concept. Geophysical Research Letters, 2007, 34 (13), pp.L13702. 10.1029/2007gl029678 . hal-03190520

\section{HAL Id: hal-03190520 \\ https://hal.science/hal-03190520}

Submitted on 6 Apr 2021

HAL is a multi-disciplinary open access archive for the deposit and dissemination of scientific research documents, whether they are published or not. The documents may come from teaching and research institutions in France or abroad, or from public or private research centers.
L'archive ouverte pluridisciplinaire HAL, est destinée au dépôt et à la diffusion de documents scientifiques de niveau recherche, publiés ou non, émanant des établissements d'enseignement et de recherche français ou étrangers, des laboratoires publics ou privés. 


\title{
Impact of land cover change on surface climate: Relevance of the radiative forcing concept
}

\author{
E. L. Davin, ${ }^{1}$ N. de Noblet-Ducoudré, ${ }^{1}$ and P. Friedlingstein ${ }^{1}$ \\ Received 19 February 2007; revised 26 April 2007; accepted 31 May 2007; published 6 July 2007.
}

[1] We use the IPSL climate model to investigate biophysical impacts of Anthropogenic Land Cover Change (ALCC) on surface climate. Including both the changes in surface albedo and evapotranspiration, we find that ALCC represents a radiative forcing of $-0.29 \mathrm{~W} / \mathrm{m}^{2}$ from 1860 to 1992 and of $-0.7 \mathrm{~W} / \mathrm{m}^{2}$ from 1992 to 2100 . The simulated surface temperature response to ALCC indicates a historical cooling of $0.05 \mathrm{~K}$ and an additional cooling due to future changes of $0.14 \mathrm{~K}$, which is consistent with the sign of the radiative forcing. However, this cooling is substantially lower than the one we would have obtained if it was caused by a radiatively equivalent change in $\mathrm{CO}_{2}$ concentration. These results thus question the relevance of the radiative forcing framework in the context of land use change, since the radiative forcing due to ALCC may not be comparable to the one exerted by other anthropogenic perturbations. Citation: Davin, E. L., N. de Noblet-Ducoudré, and P. Friedlingstein (2007), Impact of land cover change on surface climate: Relevance of the radiative forcing concept, Geophys. Res. Lett., 34, L13702, doi:10.1029/2007GL029678.

\section{Introduction}

[2] Anthropogenic activities may affect climate conditions in many different ways, particularly by altering atmospheric composition of greenhouse gases (GHG). The conversion of natural ecosystems into human-dominated systems also influences climate by directly modifying the physical properties of the land surface. Modification of vegetation cover can change the absorption of solar energy by the surface, as well as its redistribution to the atmosphere as latent and sensible heat. As suggested by climate models, historical Anthropogenic Land Cover Change (ALCC), mainly consisting of forest clearing at northern mid and high latitudes, may have cooled northern hemisphere surface climate via an increase in surface albedo [e.g., Govindasamy et al., 2001; Betts, 2001; Bonan, 1997]. The effect of ALCC on future climate is unclear, deforestation is expected to intensify in tropical regions in the coming decades, and the associated decrease in evapotranspiration may result in a warmer and drier surface climate [e.g., DeFries et al., 2002]. However, large uncertainties remain regarding the possible effects of tropical deforestation in extra-tropical regions due to teleconnection processes [e.g., Gedney and Valdes, 2000].

[3] Land cover change is not imposed as a standard forcing in transient scenarios prescribed in climate models in the framework of the Fourth Assessment Report (AR4) of

\footnotetext{
${ }^{1}$ Laboratoire des Sciences du Climat et de l'Environnement, Institut Pierre Simon Laplace, UMR CEA-CNRS-UVSQ, Gif-sur-Yvette, France.

Copyright 2007 by the American Geophysical Union. 0094-8276/07/2007GL029678
}

the Intergovernmental Panel on Climate Change (IPCC). Thus far radiative forcing (RF) has been the only tool that enables a quantitative comparison of ALCC impacts with other influences on climate, such as GHG emissions. RF aims to give a measure of the global warming (or cooling) potential of any anthropogenic or natural forcings. In the context of land use change, the relevance of this metric has already been questioned as it does not account for nonradiative processes (i.e., alteration of surface heat fluxes) that may affect surface temperature, especially in the tropics [Pielke et al., 2002]. Moreover, changes in different regions can be of opposite sign, so spatial averaging may under represent the importance of ALCC impacts [Pielke et al., 2002; Kleidon, 2006]. These limitations suggest the need for a better metric and pioneering works have already explored new means for quantifying ALCC effects [e.g., Kleidon, 2006]. That said, RF still continues to be the standard measure for comparing climate forcings [Intergovernmental Panel on Climate Change (IPCC), 2001, 2007] and it is therefore important to know if this comparison could lead to a misrepresentation of ALCC effect in terms of global temperature change. This paper tests the relevance of comparing the RF due to ALCC with other forcings, such as $\mathrm{CO}_{2}$ change, and proposes some recommendations to interpret ALCC RF.

[4] To examine this issue we compare the climate sensitivity to land cover change forcing, considering both historical and future patterns of ALCC, with the climate sensitivity relative to $\mathrm{CO}_{2}$ increase. We use a coupled ocean-atmosphere-vegetation model, which has a known climate sensitivity deduced from $\mathrm{CO}_{2}$ change experiments, to determine the surface temperature change due to ALCC. Additionally we derive the RF produced by ALCC, which includes contributions from changes in albedo and evapotranspiration. To our knowledge, the contribution of evapotranspiration change to the RF exerted by ALCC has never been explicitly estimated. However, we stress that ALCC can have an impact on atmospheric water vapor content by altering evapotranspiration fluxes. This change in water vapor content influences atmospheric long wave radiation and is a direct consequence of ALCC, which should therefore be considered to be a forcing and not a feedback of the climate system.

\section{Climate Simulations and Radiative Forcing Calculations}

[5] We use the "Institut Pierre Simon Laplace" climate model (IPSL-CM4) [Marti et al., 2005], which couples the LMDZ4 atmospheric General Circulation Model (GCM) [Hourdin et al., 2006] with the ORCA/OPA ocean GCM [Madec et al., 1998], the LIM sea ice model [Fichefet and 

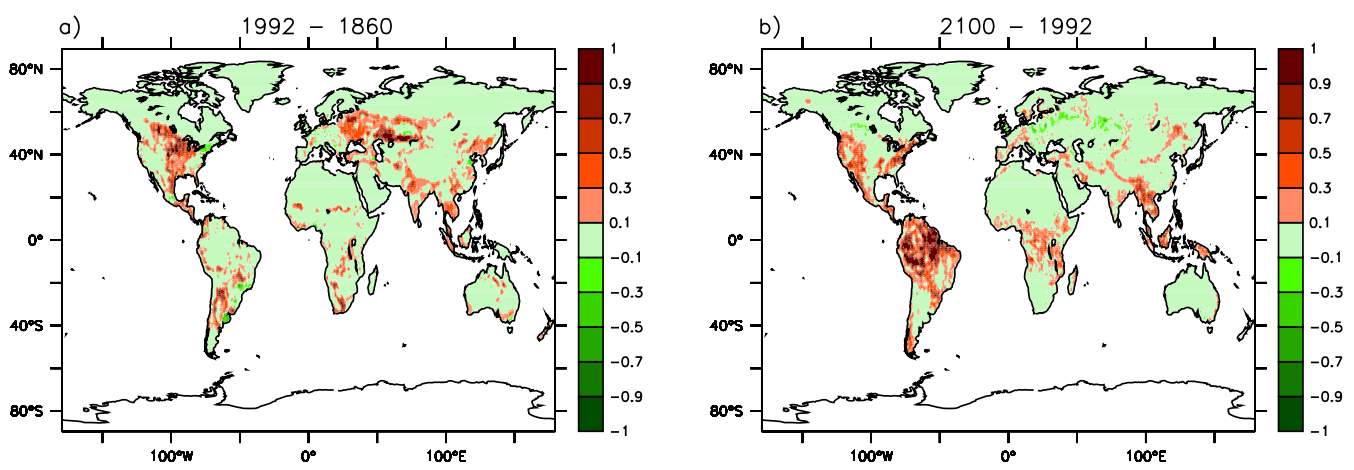

Figure 1. Total change in anthropogenic land fraction (crops + pastures) (a) from 1860 to 1992 and (b) from 1992 to 2100 .

Maqueda, 1997] and the ORCHIDEE land surface model [Krinner et al., 2005]. No flux corrections are applied and the model is run at a resolution of $3.75^{\circ} \times 2.5^{\circ}$, with 19 vertical levels in the atmosphere. The ocean has 31 vertical levels and a horizontal resolution of roughly $2^{\circ}$ with higher latitudinal resolution of $0.5^{\circ}$ in the equatorial ocean. The ORCHIDEE land surface scheme describes both biophysical processes and the terrestrial carbon cycle. The vegetation phenology is not prescribed and Leaf Area Index (LAI), which is a key variable for biophysical exchanges between the biosphere and the atmosphere, is computed from photosynthetic activity and carbon allocation to the vegetation compartments. In this version of ORCHIDEE, crops are treated as natural grassland, with slightly enhanced photosynthetic capacity, adapted maximum possible LAI and slightly modified critical temperature and humidity parameters for phenology [Krinner et al., 2005].

[6] To investigate the effect of ALCC on climate we perform three simulations, all with GHG concentrations and aerosols set to preindustrial values. Simulations referred as PAST, PRES and FUTU have prescribed pre-industrial (1860), present day (1992) and future (2100) vegetation distributions, respectively. Past and present day vegetation maps have crop areas from Ramankutty and Foley [1999], and anthropogenic pastures from Goldewijk [2001]. Future anthropogenic land areas are based on results from the IMAGE2.2 model [Alcamo et al., 1994] which projects land cover change in response to a "business as usual" economical scenario (i.e., A2 scenario). All crop and pasture areas are combined with the present-day natural vegetation cover from Loveland et al. [2000]. The resulting datasets show that past ALCC mainly affected temperate regions whereas future change will greatly impact tropical regions such as the Amazonian forest and to a lesser extent northern mid-latitudes (Figure 1). Our three simulations were initialized from a pre-existing control run and spun up for 150 years until equilibrium. The next 50 years were averaged and analyzed in this study.

[7] We also calculate the RF due to past and future ALCC, considering both albedo and evapotranspiration effects. In order to obtain the change in surface albedo and evapotranspiration primarily attributable to ALCC and not that affected by atmospheric feedbacks, we run three additional simulations with the ORCHIDEE land surface model not coupled to the GCM, but forced with the climatology of the simulation PAST. These simulations have prescribed pre-industrial, present day and 2100 vegetation. Given the change in surface albedo and evapotranspiration from preindustrial to present day and from present day to 2100 , we were then able to calculate the corresponding RFs using the radiative transfer scheme of the LMDZ model. The evapotranspiration change was first converted into a change in atmospheric water vapor content, following the methodology described by Boucher et al. [2004]. The change in water vapor content was homogeneously distributed throughout the tropospheric column and was set in proportion to the spatial pattern of evapotranspiration change. Our estimate of the RF due to change in evapotranspiration does not account for potential change in cloudiness. We consider the change in water vapor to be the initial forcing mechanism and the subsequent change in clouds to be part of the climate response.

\section{Results}

\subsection{Radiative Forcing of ALCC}

[8] The total annual mean RF due to ALCC between the pre-industrial and present day is $-0.29 \mathrm{~W} / \mathrm{m}^{2}$ (Table 1 ). This includes a contribution of $-0.22 \mathrm{~W} / \mathrm{m}^{2}$ from the surface albedo change, which is consistent with latest estimates of $-0.2 \pm 0.2 \mathrm{~W} / \mathrm{m}^{2}$ as reviewed in the IPCC AR4 [IPCC, 2007]. The change in atmospheric water vapor

Table 1. RF, Temperature Response, and Climate Sensitivity Relative to Past and Future ALCC ${ }^{\mathrm{a}}$

\begin{tabular}{lcccccc}
\hline \multicolumn{1}{c}{ Simulations } & $\Delta F_{\text {alb }}, \mathrm{W} / \mathrm{m}^{2}$ & $\Delta F_{\text {vap }}, \mathrm{W} / \mathrm{m}^{2}$ & $\Delta F_{A L C C}, \mathrm{~W} / \mathrm{m}^{2}$ & $\Delta T_{s}, \mathrm{~K}$ & $\lambda_{\text {alb }}, \mathrm{K} /\left(\mathrm{W} \mathrm{m}^{-2}\right)$ & $\lambda_{A L C C}, \mathrm{~K} /\left(\mathrm{W} \mathrm{m}^{-2}\right)$ \\
\hline PRES - PAST & -0.22 & -0.07 & -0.29 & $-0.05^{\mathrm{b}}$ & 0.52 & 0.3 \\
FUTU - PRES & -0.55 & -0.15 & -0.7 & $-0.14^{\mathrm{b}}$ & 0.38 & 0.27 \\
\hline
\end{tabular}

${ }^{\mathrm{a}} \Delta F_{\text {alb }}, \Delta F_{\text {vap }}$, and $\Delta F_{A L C C}$ are the RFs due to, respectively, albedo change, water vapor change, and both albedo and water vapor changes; $\Delta T_{s}$ is the surface temperature change; $\lambda_{\text {alb }}$ and $\lambda_{A L C C}$ are the equilibrium climate sensitivities respectively calculated relative to the albedo forcing and to the total forcing as $\Delta T_{s} /(\Delta F-\Delta R)$, where $\Delta R$ is the change in the net radiative flux at TAO.

${ }^{\mathrm{b}}$ Temperature changes are statistically significant above the $90 \%$ confidence level, as indicated by a t-test. 

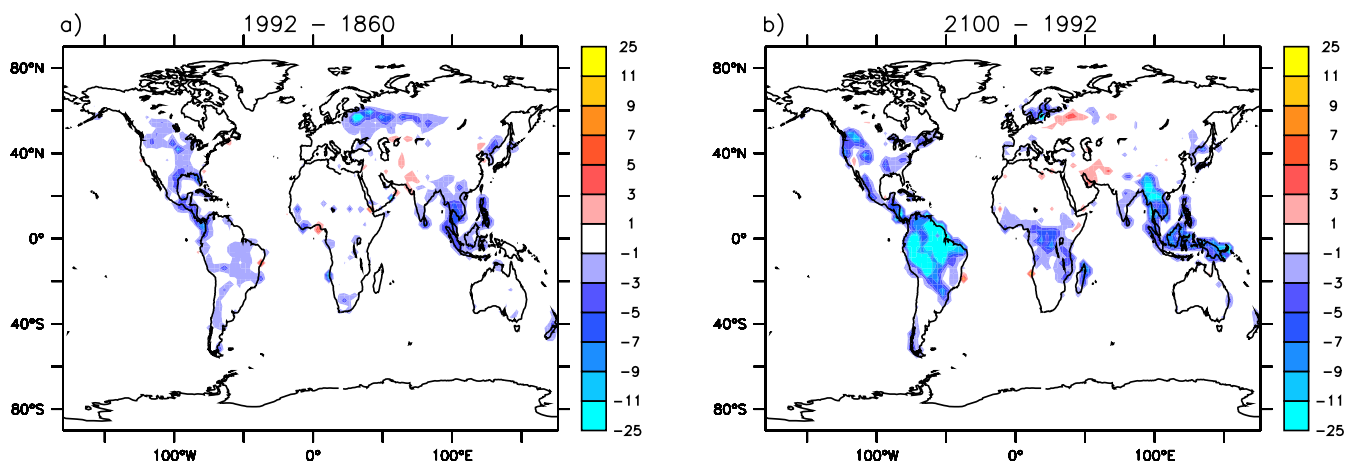

Figure 2. Annual mean RF $\left(\mathrm{W} / \mathrm{m}^{2}\right)$ due to ALCC, based on changes in albedo and evapotranspiration (a) from 1860 to 1992 and (b) from 1992 to 2100.

that arises from reduced evapotranspiration accounts for $-0.07 \mathrm{~W} / \mathrm{m}^{2}$. At the end of the next century, ALCC could exert an additional $\mathrm{RF}$ of $-0.7 \mathrm{~W} / \mathrm{m}^{2}$, with a contribution of $-0.55 \mathrm{~W} / \mathrm{m}^{2}$ due to albedo change and of $-0.15 \mathrm{~W} / \mathrm{m}^{2}$ owing to evapotranspiration decrease. The greater magnitude of future forcing is primarily linked to the intensity of land conversion, which is twice as important in the future scenario as compared to the past century.

[9] The spatial pattern of the annual mean RF indicates that past ALCC principally affected northern mid-latitudes, with maximum values exceeding $-10 \mathrm{~W} / \mathrm{m}^{2}$ over Eastern Europe (Figure 2). Positive values of around $+2 \mathrm{~W} / \mathrm{m}^{2}$, associated with a decrease in albedo, occur in the Middle East where bare soil-dominated landscapes were locally converted to pastures or crops. In the next century, most of the forcing due to ALCC occurs in the tropics and can be as high as $-20 \mathrm{~W} / \mathrm{m}^{2}$ over Amazonia. Locally positive values of around $+3 \mathrm{~W} / \mathrm{m}^{2}$ are due to conversion of bare soil in the Middle East and to forest regrowth in Eastern Europe.

\subsection{Climate Simulations}

[10] Although land conversion occurs at different locations (i.e., mid-latitudes or tropics), ALCC induces a global cooling of climate in both past and future scenarios, which is consistent in sign with the estimated radiative forcings. The global mean temperature change reaches $-0.05 \mathrm{~K}$ in PRES, compared to PAST and $-0.14 \mathrm{~K}$ in FUTU, compared to PRES (Table 1).

[11] Geographically, surface cooling is mostly centered at northern mid-latitudes in the historical case and it affects a wider latitudinal range in the future scenario (Figure 3).

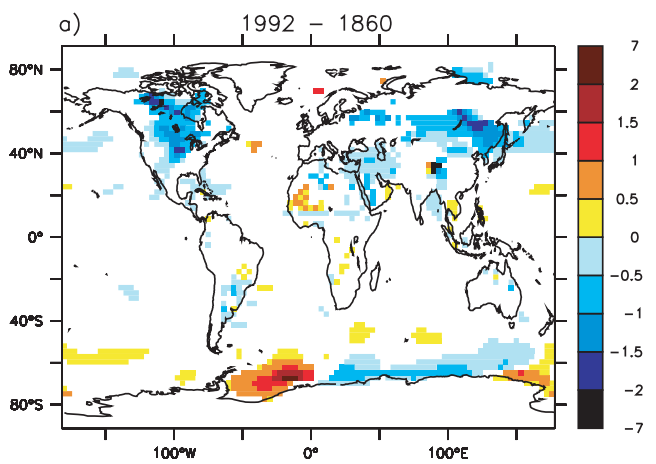

Moreover, in the future scenario a noticeable surface warming occurs over Amazonia because of the reduced evapotranspiration flux and the subsequent increase in sensible heat, which is consistent with previous studies [e.g., Feddema et al., 2005; DeFries et al., 2002].

\subsection{Climate Sensitivity to ALCC}

[12] Climate sensitivity $(\lambda)$ can be derived from the following ratio: $\Delta T_{s} /(\Delta F-\Delta R)$, where $\Delta T_{s}$ and $\Delta F$ are the surface temperature change and the global mean RF respectively, and $\Delta R$ represents the change in net radiation at the top of the atmosphere (TOA). $\Delta R$ must be considered in order to account for the long term response of the ocean which implies that the effective surface temperature response may differ from the equilibrium surface temperature change. We determine a climate sensitivity to ALCC forcing $\left(\lambda_{A L C C}\right)$ close to $0.3 \mathrm{~K} /\left(\mathrm{W} \mathrm{m}^{-2}\right)$ (Table 1$)$, which means that for a change in vegetation cover producing a forcing of $1 \mathrm{~W} / \mathrm{m}^{2}$, global temperature will increase by $0.3 \mathrm{~K}$. The same sensitivity applies for both past and future scenarios suggesting that, globally, surface climate responds consistently to tropical or extra-tropical land conversion. On the other hand, previous work indicated that the equilibrium climate sensitivity of the IPSL-CM4 model, determined from $\mathrm{CO}_{2}$-doubling experiments, is slightly above $1 \mathrm{~K} /\left(\mathrm{W} \mathrm{m}^{-2}\right)$ [Forster and Taylor, 2006]. The results of our study therefore indicate that ALCC can induce a weaker temperature response than a radiatively equivalent change in $\mathrm{CO}_{2}$ concentration.

[13] The RF exerted by ALCC is generally calculated by considering only the change in albedo [e.g., Betts, 2001], whereas we consider also the RF due to change in water

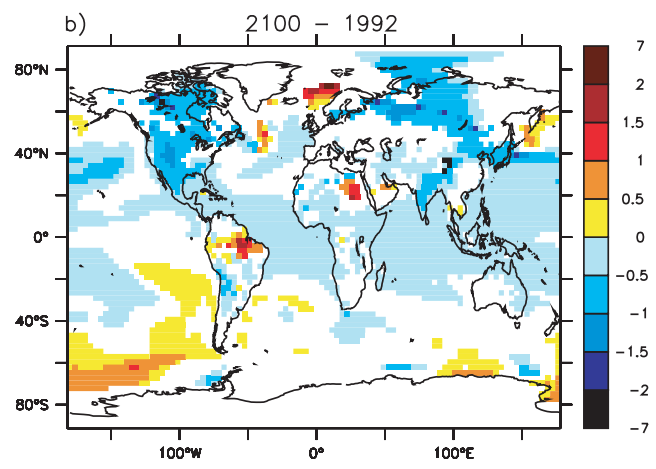

Figure 3. Change in annual mean surface temperature (K) (a) from 1860 to 1992 and (b) from 1992 to 2100. A t-test was used to discard grid points with statistical significance lower than the $95 \%$ confidence level. 
vapor. So for consistency with previous studies, we also derived $\lambda_{a l b}$, the climate sensitivity calculated solely from the albedo RF (Table 1). This way of calculating climate sensitivity leads to somewhat higher values (for both historical and future scenarios) as the forcing exerted by albedo change alone is slightly lower than the total ALCC forcing. However, it does not change the conclusion that climate sensitivity to ALCC is smaller than that due to $\mathrm{CO}_{2}$ forcing.

[14] The smaller climate sensitivity to ALCC forcing can be interpreted as the consequence of (1) the spatial distribution of ALCC and (2) the role of non-radiative processes. The first point questions the dependence of climate sensitivity to the geographical distribution of the forcing mechanism. Unlike well-mixed GHG, ALCC occurs at local to regional scales and at latitudes less than 60 degrees. In this respect, Hansen et al. [1997] presented instructive results showing that if forcings are confined to low latitudes, then climate sensitivity is substantially reduced as the initiation of cryospheric feedbacks at high latitudes is not permitted. To give an order of magnitude of the importance of high latitude feedbacks in the IPSL-CM4 model, we analysed the temperature response to a doubling of $\mathrm{CO}_{2}$ in simulations prepared in the framework of the IPCC AR4. We find that the global mean temperature change, and hence climate sensitivity, is $20 \%$ lower when the surface temperature change at high latitudes (poleward to $60^{\circ}$ ) is considered as zero. This suggests that the absence of high latitude feedbacks cannot explain a reduction of more than $20 \%$ of the climate sensitivity in the IPSL-CM4 model. The second cause of the reduced climate sensitivity involves non-radiative processes (i.e., change in the partitioning between latent and sensible heat) that compete with the radiative cooling due to change in albedo and water vapor. Converting forest to grass tends to decrease evapotranspiration and enhance sensible heating, therefore warming the near-surface atmosphere. This effect is especially relevant in tropical regions (see the surface warming in the future scenario over Amazonia in Figure 3) and during the summer months in the northern hemisphere extratropics [Kleidon, 2006]. To address the importance of this effect we performed additional sensitivity experiments with the IPSL-CM4 model, contrasting a forested earth with a drastic scenario of global deforestation. In a first experiment, only the effect of albedo change was accounted for and in a second experiment, the total biophysical effect was considered. Results show that, compared to the simulation that only considers albedo change, the global mean temperature decrease is $30 \%$ lower when all biophysical effects are accounted for, despite the reduction in evapotranspiration (which tends to cool the climate further). This means that non-radiative processes decrease the climate sensitivity to ALCC by at least $30 \%$ or more in these experiments. Based on these results we conclude that non-radiative effects are likely to contribute the major part of the reduction of the climate sensitivity to ALCC compared to $\mathrm{CO}_{2}$-related climate sensitivity.

\section{Conclusions}

[15] In this paper we show that historical as well as future ALCC produce a negative RF, mainly due to the surface albedo increase and to a lesser extent the evapotranspiration decrease. Although surface climate responds to this forcing by a global cooling, the simulated cooling is lower than if the perturbation was caused by a radiatively equivalent change in $\mathrm{CO}_{2}$. We interpret this result to be a consequence of (1) the spatial scale of ALCC forcing and (2) the effect of non-radiative processes which affect the partitioning of surface heat fluxes. Therefore, comparing the radiative forcing exerted by ALCC with other forcings may not be fully credible and this metric should be interpreted with caution. We recommend the use of the concept of "climate efficacy" proposed by Hansen et al. [2005] when comparing the RF due to ALCC with other forcing agents. The climate efficacy, defined as the ratio between the climate sensitivity to a given forcing and the climate sensitivity to $\mathrm{CO}_{2}$ forcing, can be viewed as a factor that corrects any forcing whose efficacy differs from $\mathrm{CO}_{2}$ forcing. Based on our results, the calculated RFs should be multiplied by a factor of 0.3 (i.e. $\lambda_{A L C C} / \lambda_{C O 2}=0.3 / 1$ ) for proper comparison with other forcings. Moreover, we stress that in order to better assess the robustness of our results, it is necessary to perform similar analysis with a range of coupled climate models.

[16] Acknowledgments. We thank Jean-Louis Dufresne, Richard Betts, and one anonymous reviewer for their constructive comments. We are grateful to Andrew Friend and Alessandro Tagliabue who helped us improve the clarity of the manuscript. Part of this research was supported by the Agence Nationale de la Recherche (ANR) through the DIVA project and by the EU funded project ENSEMBLES (GOCE-CT-2003-505539). The computing time was provided by the Commissariat à l'Energie Atomique (CEA).

\section{References}

Alcamo, J., et al. (1994), Modeling the global society-biosphere-climate system: 2. Computed scenarios, Water Air Soil Pollut., 76(1-2), 37-78.

Betts, R. A. (2001), Biogeophysical impacts of land use on present-day climate: Near-surface temperature change and radiative forcing, Atmos. Sci. Lett., 2(1-4), 39-51.

Bonan, G. B. (1997), Effects of land use on the climate of the United States, Clim. Change, 37(3), 449-486.

Boucher, O., G. Myhre, and A. Myhre (2004), Direct human influence of irrigation on atmospheric water vapour and climate, Clim. Dyn., 22(6-7), $597-603$.

DeFries, R. S., L. Bounoua, and G. J. Collatz (2002), Human modification of the landscape and surface climate in the next fifty years, Global Change Biol., 8(5), 438-458.

Feddema, J. J., K. W. Oleson, G. B. Bonan, L. O. Mearns, L. E. Buja, G. A. Meehl, and W. M. Washington (2005), The importance of land-cover change in simulating future climates, Science, 310(5754), 1674-1678.

Fichefet, T., and M. A. M. Maqueda (1997), Sensitivity of a global sea ice model to the treatment of ice thermodynamics and dynamics, J. Geophys. Res., 102(C6), 12,609-12,646.

Forster, P. M., and K. E. Taylor (2006), Climate forcings and climate sensitivities diagnosed from coupled climate model integrations, J. Clim., $19,6181-6194$.

Gedney, N., and P. J. Valdes (2000), The effect of Amazonian deforestation on the Northern Hemisphere circulation and climate, Geophys. Res. Lett., 27(19), 3053-3056.

Goldewijk, K. K. (2001), Estimating global land use change over the past 300 years: The Hyde database, Global Biogeochem. Cycles, 15(2), 417-433.

Govindasamy, B., P. B. Duffy, and K. Caldeira (2001), Land use changes and Northern Hemisphere cooling, Geophys. Res. Lett., 28(2), 291-294.

Hansen, J., M. Sato, and R. Ruedy (1997), Radiative forcing and climate response, J. Geophys. Res., 102(D6), 6831-6864.

Hansen, J., et al. (2005), Efficacy of climate forcings, J. Geophys. Res., 110, D18104, doi:10.1029/2005JD005776.

Hourdin, F., et al. (2006), The LMDZ4 general circulation model: Climate performance and sensitivity to parametrized physics with emphasis on tropical convection, Clim. Dyn., 27(7-8), 787-813.

Intergovernmental Panel on Climate Change (2001), Climate Change 2001. The Scientific Basis. Contribution of Working Group I to the Third Assesment Report of the Intergovernmental Panel on Climate Change, 881 pp., Cambridge Univ. Press, New York. 
Intergovernmental Panel on Climate Change (IPCC) (2007), Climate Change 2007: The Physical Science Basis, Contribution of Working Group I to the Fourth Assessment Report of the Intergovernmental Panel on Climate Change, Summary for Policymakers, World Meteorol. Organ., Geneva, Switzerland.

Kleidon, A. (2006), The climate sensitivity to human appropriation of vegetation productivity and its thermodynamic characterization, Global Planet. Change, 54(1-2), 109-127.

Krinner, G., N. Viovy, N. de Noblet-Ducoudré, J. Ogée, J. Polcher, P. Friedlingstein, P. Ciais, S. Sitch, and I. C. Prentice (2005), A dynamic global vegetation model for studies of the coupled atmosphere-biosphere system, Global Biogeochem. Cycles, 19, GB1015, doi:10.1029/ 2003GB002199.

Loveland, T. R., B. C. Reed, J. F. Brown, D. O. Ohlen, Z. Zhu, L. Yang, and J. W. Merchant (2000), Development of a global land cover characteristics database and IGBP DISCover from $1 \mathrm{~km}$ AVHRR data, Int. $J$ Remote Sens., 21(6-7), 1303-1330.

Madec, G., P. Delecluse, M. Imbard, and M. Lévy (1998), OPA 8.1, Ocean General Circulation Model reference manual, Note du Pôle de Modélisation 11, Inst. Pierre-Simon Laplace, Paris, France.
Marti, O., et al. (2005), The new IPSL climate system model: IPSL-CM4, Note du Pôle de Modélisation 26, Inst. Pierre-Simon Laplace, Paris, France.

Pielke, R. A., G. Marland, R. A. Betts, T. N. Chase, J. L. Eastman, J. O. Niles, D. D. S. Niyogi, and S. W. Running (2002), The influence of landuse change and landscape dynamics on the climate system: Relevance to climate-change policy beyond the radiative effect of greenhouse gases, Philos. Trans. R. Soc. London Ser. A, 360(1797), 1705-1719.

Ramankutty, N., and J. A. Foley (1999), Estimating historical changes in global land cover: Croplands from 1700 to 1992, Global Biogeochem. Cycles, 13(4), 997-1027.

E. L. Davin, N. de Noblet-Ducoudré, and P. Friedlingstein, Laboratoire des Sciences du Climat et de l'Environnement, Institut Pierre Simon Laplace, UMR CEA-CNRS-UVSQ, Orme des merisiers, F-91191 Gif-surYvette, France. (edouard.davin@cea.fr) 